\title{
Origin of grain orientation during solidification of an aluminum alloy
}

\author{
H. L. Wei, ${ }^{a}$ J. W. Elmer ${ }^{\mathrm{b}}$ and T. DebRoy ${ }^{\mathrm{a}, *}$ \\ ${ }^{\mathrm{a}}$ Department of Materials Science and Engineering, The Pennsylvania State University, \\ University Park, PA, 16802, USA. \\ ${ }^{\mathrm{b}}$ Materials Engineering Division, Lawrence Livermore National Laboratory, \\ Livermore, CA, 94550, USA
}

Abstract - The evolution of grain morphology during solidification of a moving aluminum alloy pool is simulated by considering heat transfer, flow of liquid metal in the molten pool and solidification parameters. The computationally efficient model consists of a 3D coupled heat transfer and fluid flow simulation to predict the molten pool shape and temperature field, and a 2D model of grain formation in the molten pool. The results demonstrate that columnar grains grow in a curved pattern rather than along straight lines from the fusion boundary towards the center of the molten pool. The calculated results are validated with independent experimental data. The computed ratio of local temperature gradient to solidification rate, $\mathrm{G} / \mathrm{R}$, is used to model the columnar to equiaxed transition during solidification. The simulated results show that only curved columnar grains are formed when the scanning speed is low $(2.0 \mathrm{~mm} / \mathrm{s})$. In contrast, a transition from curved columnar to equiaxed morphologies occurs at the higher scanning speeds of $8.0 \mathrm{~mm} / \mathrm{s}$ and $11.5 \mathrm{~mm} / \mathrm{s}$, with higher equiaxed grain fraction at higher speed. The similarities between the physical processes governing fusion welding and additive manufacturing (AM) make the model capable of predicting grain orientation in both processes.

Keywords: Solidification; Grain growth; Additive manufacturing; Welding; Aluminum alloy 


\section{Introduction}

In both additive manufacturing and fusion welding, a moving pool of molten metal leaves behind a unique solidification pattern depending on the temperature field near the solidifying interface and the grain orientation of the substrate [1-6]. Control of microstructure is critical to achieve the desired mechanical and chemical properties of the fabricated components. Moving heat sources such as a laser beam, an electron beam or an electric arc create a fusion zone (FZ), a heat affected zone (HAZ) and microstructural gradients that affect the properties and performances of the fabricated product. Understanding the thermal history that creates these gradients is important, and has been computed through 3D modeling of heat transfer and fluid flow during welding. HAZ and FZ models need to be developed to connect the temperature history and the microstructural changes that occur. HAZ models have been created through kinetic models of phase transformations and Monte Carlo modeling [7-9]. But comparatively little has been done to predict the FZ microstructure.

The grain structure of the weld metal in the FZ significantly affects its resistance to solidification cracking and mechanical properties [10, 11]. Curved columnar grains have been observed in the FZ of aluminum, and other alloys [10, 12-15]. Equiaxed grains also form and coexist with columnar grains under some welding conditions $[10,16]$. The columnar grains are generally coarse and are characterized by fibrous texture and anisotropic mechanical properties. In contrast, equiaxed grains are usually small, do not exhibit fibrous texture, and are isotropic, with more uniform mechanical properties [17-19]. Although a large volume of experimental data have been reported about the grain morphologies in the weld metal of 
aluminum alloys, very little work has been done to simulate the evolution of curved columnar and equiaxed grains in the FZ. Furthermore, the mechanism of formation of these grains has not been thoroughly examined based on solidification theory.

The grain structure in the weld metal is predominantly controlled by the base metal grain structure and the welding conditions [20]. Initial grain growth occurs epitaxially at the partially melted grains in the base metal. Grains then grow along a certain crystallographic direction during the solidification process [21]. The preferred crystallographic directions for solidification of face-centered cubic aluminum alloys are $\langle 100\rangle$. Therefore, in polycrystalline specimens containing randomly oriented grains, preferred growth during solidification occurs when the grains oriented along $\langle 100\rangle$ directions grow along the maximum heat flow direction. The heat flow direction at the solid/liquid (S/L) interface is dependent on the local curvature of the boundary of the molten pool which depends on various welding variables $[22,23]$. Columnar structures in the weld metal can be promoted from the competitive growth during the solidification process whereby dendrites that are more aligned with the temperature gradient outgrow slower growing misaligned dendrites [20]. Under certain solidification conditions the curved columnar grains may transit to equiaxed grains at the center region of the weld during their growth process in some aluminum alloys $[10,13]$. The local solidification conditions at the $\mathrm{S} / \mathrm{L}$ interface of the molten pool must be known to predict this transition.

In this paper a model is developed to calculate the geometric aspects of the FZ grains. Elemental segregation and the finer scale of solidification that describes the formation of cells or dendrites within the grains are not included for simplicity, but can be added later if higher 
fidelity models are required. It is shown that a model with such simplification can give realistic simulation of the grain morphology and orientation evolution during the solidification process while being computationally tractable. The model is validated with independent experimental data [13-15] for grain growth at various scanning speeds.

\section{Models and methodology}

The modeling of grain morphology and orientation evolution of aluminum alloys is implemented by incorporating a 3D heat transfer and fluid flow model $[24,25]$ and a $2 \mathrm{D}$ grain growth model. The temperature and velocity fields, solidification parameters and the molten pool geometries are calculated using the well-tested, three dimensional, transient, heat transfer and fluid flow model. The computed results of temperature fields and solidification parameters are then used as input for the grain growth model, which simulates the evolution of grain structures. This grain growth model is newly developed to study the grain morphology and orientation evolution process in the FZ. The salient features of the models and the computational scheme for the grain growth process are presented below. Gas Tungsten Arc (GTA) welding of aluminum-magnesium-silicon alloy 6082 is considered as an example to illustrate the evolution of grain morphology and orientation.

\section{A. Heat transfer and fluid flow model}

A 3D heat transfer and fluid model has been used to simulate the temperature and velocity fields by solving the equations of conservation of mass, momentum and energy. The details of the governing equations, boundary conditions and the algorithm are available in our previous papers $[24,26-28]$ and are not repeated here. The composition of the aluminum 
alloy is presented in Table 1. The data used for the numerical calculation are included in Table 2 and the welding parameters are listed in Table 3.

\section{B. Grain growth model}

(1) Assumptions

The grain growth model focuses on the geometric aspects of grains and macrostructure in the FZ. The following simplifying assumptions are made to achieve computational efficiency:

(1) The formation of planar, cellular or dendritic structures inside the grains is not considered.

(2) Solute redistribution and local heat transfer in micro scale during the grain growth process are not considered. (3) The segregation of solutes is disregarded. (4) The competitive growth among grains with different crystallographic orientations is not considered for simplicity.

It is assumed that the columnar grains grow along location dependent directions and speeds as the molten pool moves along, and that the shape and size of the pool does not change with time when steady state is attained. However, more grains grow as the pool moves along at a constant speed. Geometrically, it appears that the grains are "pulled" by the curvature of the trailing edge of the molten pool which has a major influence on their shapes. The incremental growth of grains for each time step modifies the local directions and velocities, which change for all the grains as they tend to align parallel to the scanning direction toward the center of the molten pool.

The model does not predict the critical $G / R$ value for transition from columnar to equiaxed grains. The existing theories for such transitions were developed for castings considering one dimensional heat conduction without any rigorous fluid flow considerations. 
These difficulties are apparent from the previous research [14], [29]. Here the formation of equiaxed grains in the FZ are determined from the critical G/R values obtained from independent previous research [14].

(2) Grids and time steps

Grids are spaced uniformly $10 \mu \mathrm{m}$ apart in both $\mathrm{x}$ - and y-directions for the grain growth calculations. The grids used in the heat transfer and fluid flow calculations are non-uniform and 5 to10 times larger in size. The temperature field obtained from the heat transfer and fluid flow model is interpolated to obtain local temperatures at each grid node of the finer grids used in the grain growth model. The time step $\Delta t$ used in the calculation of grain growth is obtained by:

$\Delta t=C \frac{a}{R_{\max }}$

where $C$ is a constant greater than $1, a$ is the mesh size, and $R_{\max }$ is the maximum solidification rate or the scanning speed. The molten pool moves a distance of $C \cdot a$ in every time step.

(3) Solidification directions and rates

The solidification direction is assumed to be parallel to the local maximum heat flow direction on the trailing side of the weld pool. The heat flow direction at any location of the $\mathrm{S} / \mathrm{L}$ interface of the molten pool is normal to the interface, and can be calculated by $[5,30]$ : $\nabla T=\frac{\partial T}{\partial x} i+\frac{\partial T}{\partial y} j+\frac{\partial T}{\partial z} k$

(2) where $T$ is temperature and $i, j$ and $k$ are unit vectors in the welding direction, $\mathrm{x}$, width 
direction, $y$ and the vertical depth direction, $z$, respectively. The coordinate system is shown in Figure 1. The temperature gradient $G$ is calculated by:

$G=\|\nabla T\|$

Each columnar grain grows along its center axis, which is a line passing through the location of epitaxial regrowth and having the slope of $\tan (\alpha)$. The angle $\alpha$ between the welding direction and the maximum heat flow direction is obtained from the temperature field:

$\cos \alpha=\frac{-\partial T / \partial x}{G}$

The calculations of grain growth process are done in 2D for computational simplification and ease of visualization, although the temperature and velocity fields are computed with a 3D heat transfer and fluid flow model. As the work in this paper focuses on the grain growth in the horizontal x-y plane of the weld, so the z-direction components in equation (2) are taken as zero.

The local solidification rate $R_{l o c}$ is the speed at the $\mathrm{S} / \mathrm{L}$ interface on the trailing side of the molten pool moving at steady state. Its value is position dependent and changes from $R_{l o c}=0$ on the edge of the weld to $R_{l o c}=R_{\max }$ at the weld centerline. These parameters are schematically shown in Figure 1. The solidification rate is calculated as:

$R_{l o c}=R_{\max } \cdot \cos \alpha$

where $R_{\max }$ is the maximum solidification rate, which is the same as the scanning speed.

(4) Grain morphology

For the aluminum alloy welds examined in this work, either only the curved columnar grains or a combination of both the curved columnar and equiaxed grains form in a single 
weld. The solidification parameter $\mathrm{G} / \mathrm{R}$ determines the selection between the curved columnar grains and the equiaxed grains. Equiaxed grains can be formed if the local G/R value is lower than the critical value to form equiaxed dendrites and vice versa.

Various indices are allocated to the curved columnar grains to identify and track each grain. These indices are also allocated a color for the display of the grain morphologies. The equiaxed grains grow randomly near the center region of the weld. Various indices are also randomly allocated to different equiaxed grains for their display.

\section{C. Calculation procedure}

The steps involved in the calculation of the grain morphologies and orientations during the GTA welding process are listed below.

1. The temperature and velocity fields in the molten pool are calculated using the heat transfer and fluid flow model.

2. The local solidification direction and rate $R_{l o c}$ at the $\mathrm{S} / \mathrm{L}$ interface are computed from equations (2) and (5).

3. The solidification parameter $G / R_{l o c}$ at the $\mathrm{S} / \mathrm{L}$ interface is calculated from the heat transfer and fluid flow model for the determination of local grain morphology.

4. The time step for the grain growth model is calculated from equation (1).

5. The grain sizes in the solid region at the interface are prescribed from the experimental data [14]. This assumption allows the width of the columnar grains to be estimated without a separate model for grain growth in the solid region. 
6. As the fusion boundary relocates after a time step, the grains are assumed to grow from the $\mathrm{S} / \mathrm{L}$ interface along the maximum local heat flow direction. The columnar grains continue to grow in curved shapes unless equiaxed grains are formed closer to the weld centerline.

7. When the $G / R$ ratio indicates formation of equiaxed grains, the growth of curved columnar grains is terminated, typically near the weld center region. The columnar to equiaxed transition is more prominent at high scanning speeds with low G/R values.

\section{Results and discussion}

Figures 2 (a), (b) and (c) show the calculated temperature and velocity fields in the top horizontal molten pool surfaces $(\mathrm{z}=3 \mathrm{~mm})$ of GTA welds of aluminum alloy 6082 for the scanning speeds of $2.0 \mathrm{~mm} / \mathrm{s}, 8.0 \mathrm{~mm} / \mathrm{s}$ and $11.5 \mathrm{~mm} / \mathrm{s}$, respectively. Note that these are all fully penetrated welds for different scanning speeds. The center of the arc heat source is located at $\mathrm{x}=24 \mathrm{~mm}$ for all cases. At the top surface of the molten pool, the liquid metal flows from the center to the periphery of the molten pool driven by Marangoni stress, which results from the spatial gradient of surface tension due to local temperature variation on the surface. The reference vectors are shown in the figures for indication of the magnitude of the velocities of the liquid metal. The velocities are of the order of $500 \mathrm{~mm} / \mathrm{s}$ and at these velocities most of the heat is carried by convection which is the primary mechanism of heat transfer within the molten pool.

At a low scanning speed of $2.0 \mathrm{~mm} / \mathrm{s}$, the molten pool shape is close to a semicircle in the $x-y$ plane as shown in Figure 2 (a). The rear and the front boundaries of the molten pool are almost equidistant from the arc center. However, when the scanning speed increases to 
$11.5 \mathrm{~mm} / \mathrm{s}$, the temperature contours in the front of the molten pool are compressed and those behind the molten pool are expanded. The distance from the arc center to the rear boundary now is 1.6 times of that between the arc center and the front boundary. The weld half-width decreases from $4.2 \mathrm{~mm}$ to $3.5 \mathrm{~mm}$. Such shifts in the positions of the isotherms with scanning speed indicate changes in the heat flow directions which in turn affect the grain growth pattern in the FZ significantly.

Figures 2 (d), (e) and (f) show the calculated temperature and velocity fields in the horizontal $x-y$ planes at the mid-depth $(z=1.5 \mathrm{~mm})$ of the welds. The distributions of the isotherms in these planes are similar to those in the top horizontal $x-y$ planes. The liquid metal flow pattern indicates considerable mixing and the three dimensional nature of the flow although the isotherms are similar in shape to those of the top surfaces. The temperature field data in these $\mathrm{x}-\mathrm{y}$ planes are used for the grain growth modeling.

The heat transfer and fluid flow model was validated by comparing the computed and the experimentally observed transverse section geometry shown in Figure 3. Both the shape and dimensions of the weld computed from the 3D heat transfer and fluid flow model agree well with the experimental result and the agreement indicates that the computed heat flow directions are correct.

Figure 4 illustrates the formation of curved columnar grains in the horizontal x-y plane of the FZ. Assuming one columnar grain starts to grow from $P_{1}$, its growth direction between $P_{1}$ and $P_{2}$ is determined by the heat flow direction at $P_{1}$, as indicated by the solid arrow. The local angle between the heat flow direction and the scanning direction is $\alpha_{1}$. After the grain reaches $P_{2}$, its growth direction in between $P_{2}$ and $P_{3}$ is determined by the solidification 
direction calculated at $P_{2}$ which is indicated by the dashed arrow. The local angle between the heat flow direction and the scanning direction is $\alpha_{2}$. This local angle changes into $\alpha_{3}$ when the grain reaches $P_{3}$. Therefore, the local solidification direction of a columnar grain changes with the movement of the molten pool. The local solidification directions at $P_{1}, P_{2}$ and $P_{3}$ are calculated using equation (2) and the angles $\alpha_{1}, \alpha_{2}$, and $\alpha_{3}$ are calculated using equation (4). The angle changes with time and columnar grains grow in a curved, rather than straight shape.

When a columnar grain grows from $P_{1}$ to $P_{2}$ to $P_{3}$, the local solidification rate $R$ accelerates progressively because of the decrease in the angle $\alpha$ closer to the weld centerline. Figure 5 shows the calculated values of $\mathrm{R}$ at the $\mathrm{S} / \mathrm{L}$ interface in the horizontal $\mathrm{x}-\mathrm{y}$ plane of the FZ at the mid-depth $(\mathrm{z}=1.5 \mathrm{~mm})$. It is clear that $\mathrm{R}=0$ for epitaxial regrowth on the edge of the weld, and that $\mathrm{R}$ increases as the grains grow towards the centerline of the weld. In addition, $\mathrm{R}$ increases in all locations as the scanning speed of the weld is increased. These variations in $\mathrm{R}$ affect the values of the cooling rate, which equal to the product of GR, and the solidification parameter, which is equal to the ratio of $G / R$.

The calculated cooling rates, GR, at the S/L interface across the FZ at different scanning speeds of 2.0, 8.0 and $11.5 \mathrm{~mm} / \mathrm{s}$ are shown in Figure 6. The cooling rate is shown to increase with both scanning speed and distance from the weld edge. The maximum value of cooling rate is at the weld centerline which is consistent with the observation reported in the literature [16], and is zero at the edge of the weld. The cooling rate varies in such a way due to the significant change of solidification rate $\mathrm{R}$ and the temperature gradient $\mathrm{G}$ at the $\mathrm{S} / \mathrm{L}$ interface across the weld. The scale of the microstructural features are inversely correlated with the 
local cooling rates [16]. These results can be compared to experimental data that show the presence of small equiaxed grains in the weld center region at high scanning speeds [13]. These equiaxed grains can form when the G/R ratio decreases below a critical value. Figure 7 shows the calculated G/R values at the $\mathrm{S} / \mathrm{L}$ interface across the FZ for the three different scanning speeds, indicating that $G / R$ decreases with the distance from the weld edge. $G / R$ is further shown to decrease with the increase in overall scanning speed, and these results will be correlated to the formation of equiaxed grains later in this paper.

Figure 8 shows the evolution of the curved columnar grains in the horizontal $x-y$ plane at the mid-depth $(\mathrm{z}=1.5 \mathrm{~mm})$ of the weld. The temperature and velocity fields in the molten pool are also shown. The initial growth of the columnar grains takes place from the S/L interface within the molten pool. Then the columnar grains grow towards to the center of the molten pool. The growth continues while new grains are introduced and grow from the molten pool boundary with the motion of the molten pool. The trailing edge at the weld centerline moves to $\mathrm{x}=7.8 \mathrm{~mm}$ after $8.0 \mathrm{~s}$ from an initial position of $\mathrm{x}=23.8 \mathrm{~mm}$. At a scanning speed of $2.0 \mathrm{~mm} / \mathrm{s}$, the trailing edge moves a distance $16.0 \mathrm{~mm}$. The results in Fig. 8 explicitly show the formation of curved columnar grains in the FZ.

Figures 9 to 11 show the evolution of grain morphologies and orientations in horizontal planes of the FZ for different scanning speeds [13]. Different thermal conditions during solidification result in either curved columnar grains or a combination of curved columnar grains and equiaxed grains in the weld metal. Figure 9 shows the curved columnar grains in the horizontal $\mathrm{x}-\mathrm{y}$ plane at the mid-depth $(\mathrm{z}=1.5 \mathrm{~mm})$ of the FZ at a scanning speed of 2.0 $\mathrm{mm} / \mathrm{s}$. The welding current and voltage are $170 \mathrm{~A}$ and $10.7 \mathrm{~V}$, respectively. Both the 
calculated and experimental results show that there are only columnar grains formed in this case. Experimental data show that solidification cracks can form in these locations near the weld centerline, where the elongated columnar grains exist.

Figure 10 shows the curved columnar grains as well as the equiaxed grains in the horizontal $\mathrm{x}-\mathrm{y}$ plane at the mid-depth $(\mathrm{z}=1.5 \mathrm{~mm})$ of the $\mathrm{FZ}$ with scanning speed $8.0 \mathrm{~mm} / \mathrm{s}$. The most significant difference of the grain morphologies from the last case is the presence of equiaxed grains at the center region of the weld. The curved columnar grains growing from the boundary of the molten pool are blocked by these equiaxed grains. The initial widths of the columnar grains and the diameters of the equiaxed grains are listed in Table 3. The grain morphologies shown in Figure 11 at the higher speed of $11.5 \mathrm{~mm} / \mathrm{s}$ are similar except that the grain sizes and the ratio of columnar to equiaxed grains decrease with increasing scanning speed.

Columnar grains commonly have planar, cellular or columnar dendritic substructures and equiaxed grains have equiaxed dendritic substructures [15]. The solidification parameter $G / R$ at the $\mathrm{S} / \mathrm{L}$ interface has been used to determine the morphologies of the solidification structures. Planar, cellular, columnar dendritic and equiaxed dendritic structures are formed in the sequence of decreasing values of $\mathrm{G} / \mathrm{R}$. The formation of equiaxed dendrites eliminates the columnar grains and generates equiaxed grains. Therefore, the formation of curved columnar grains and equiaxed grains can be predicted from the computed solidification parameter G/R considering different substructures in columnar and equiaxed grains. Reported data show that the G/R value for columnar to equiaxed transition of the aluminum alloy used in this study is about $9.0 \mathrm{Ks} \mathrm{mm}^{-2}[14]$. 
The regions of stability of equiaxed and columnar grains were presented in Figure 7. The scanning speed significantly affects the temperature field in the entire weldment and consequently the stability of columnar and equiaxed grains. For a fairly low scanning speed of $2 \mathrm{~mm} / \mathrm{s}$, the computed $\mathrm{G} / \mathrm{R}$ values indicate formation of only columnar grains. As the speed increases to $8 \mathrm{~mm} / \mathrm{s}$, equiaxed grains form from the weld centerline up to about $0.8 \mathrm{~mm}$ from the centerline. This region expands to about $1.6 \mathrm{~mm}$ from the weld centerline when the scanning speed increases to $11.5 \mathrm{~mm} / \mathrm{s}$.

\section{Conclusions}

The evolution of grain morphology and orientation in an aluminum alloy weld has been examined by combining a heat transfer and fluid flow model and a grain growth model. The following are the main conclusions:

(1) The integrated 3D heat transfer and fluid flow and 2D grain growth models are capable of predicting the effect of scanning speed on grain morphology evolution of an aluminum alloy during GTA welding.

(2) The simulated results demonstrate that columnar grains grow in curved rather than straight shapes from the boundary towards the center of the welds, characteristic of real weld behavior. The calculated results agree well with independent experimental data for the GTA welding 6082 aluminum alloy.

(3) Using the computed solidification parameters, the columnar to equiaxed transition of grains in the solidification structure could be predicted for various scanning speeds. The computed $G / R$ value increases with reduction in scanning speed and decreases along a distance away from the molten pool boundary. 
(4) The simulated results show that only curved columnar grains are formed when the scanning speed is $2.0 \mathrm{~mm} / \mathrm{s}$. Both curved columnar and equiaxed grains are formed when the scanning speeds are $8.0 \mathrm{~mm} / \mathrm{s}$ and $11.5 \mathrm{~mm} / \mathrm{s}$. For the conditions of welding of this alloy, columnar to equiaxed transition occurs for $\mathrm{G} / \mathrm{R}$ value lower than $9.0 \mathrm{Ks} \mathrm{mm}^{-2}$. The region with $\mathrm{G} / \mathrm{R}$ lower than this critical value expands with the increase in scanning speed, which therefore results in an increase of the ratio of equiaxed to columnar grains.

\section{Acknowledgements:}

We acknowledge the support from US Department of Energy NEUP Grant DE-NE0008280. 


\section{References:}

[1] V. Manvatkar, A. De, T. DebRoy. Heat transfer and material flow during laser assisted multi-layer additive manufacturing, J. Appl. Phys. 116 (2014) 124905.

[2] V. Manvatkar, A. De, T. DebRoy. Spatial variation of melt pool geometry, peak temperature and solidification parameters during laser assisted additive manufacturing process, Mater. Sci. Tech. 31 (2015) 924-930.

[3] G.P. Dinda, A.K. Dasgupta, J. Mazumder. Laser aided direct metal deposition of Inconel 625 superalloy: Microstructural evolution and thermal stability, Mater. Sci. Eng. A 509 (2009) 98-104.

[4] G.P. Dinda, A.K. Dasgupta, J. Mazumder. Texture control during laser deposition of nickel-based superalloy, Scripta Mater. 67 (2012) 503-506.

[5] H.L. Wei, J. Mazumder, T. DebRoy. Evolution of solidification texture during additive manufacturing, Sci. Rep. 5 (2015) 16446.

[6] T. Mukherjee, J.S. Zuback, A. De, T. DebRoy. Printability of alloys for additive manufacturing, Sci. Rep. 6 (2016) 19717.

[7] S. Mishra, T. DebRoy. Measurements and Monte Carlo simulation of grain growth in the heat-affected zone of Ti-6Al-4V welds, Acta Mater. 52 (2004) 1183-1192.

[8] S. Mishra, T. DebRoy. Grain topology in Ti-6Al-4V welds-Monte Carlo simulation and experiments, J. Phys. D. Appl. Phys. 37 (2004) 2191-2196.

[9] S. Mishra, T. DebRoy. Non-isothermal grain growth in metals and alloys, Mater. Sci. Tech. 22 (2006) 253-278. 
[10] S. Kou, Y. Le. Welding parameters and the grain-structure of weld metal - a thermodynamic consideration, Metall. Trans. A 19 (1988) 1075-1082.

[11] S.A. David, J.M. Vitek. Correlation between solidification parameters and weld microstructures, Int. Mater. Rev. 34 (1989) 213-245.

[12] S. Kou, Y. Le. Grain-structure and solidification cracking in oscillated arc welds of 5052 aluminum-alloy, Metall. Trans. A 16 (1985) 1345-1352.

[13] P. Schempp, C.E. Cross, A. Pittner, G. Oder, R.S. Neumann, H. Rooch, I. Dorfel, W. Osterle, M. Rethmeier. Solidification of GTA Aluminum Weld Metal: Part 1-Grain Morphology Dependent upon Alloy Composition and Grain Refiner Content, Weld. J. 93 (2014) 53S-59S.

[14] P. Schempp, C.E. Cross, A. Pittner, M. Rethmeier. Solidification of GTA Aluminum Weld Metal: Part 2-Thermal Conditions and Model for Columnar-to-Equiaxed Transition, Weld. J. 93 (2014) 69S-77S.

[15] P. Schempp, M. Rethmeier. Understanding grain refinement in aluminium welding, Weld. World. 59 (2015) 767-784.

[16] S. Kou. Welding metallurgy. 2nd ed., John Wiley \& Sons, Hoboken, NJ, 2003.

[17] H.B. Dong, P.D. Lee. Simulation of the columnar-to-equiaxed transition in directionally solidified Al-Cu alloys, Acta Mater. 53 (2005) 659-668.

[18] Y. Arata, F. Matsuda, S. Mukae, M. Katoh. Effect of weld soldificaiton mode on tensile properties of aluminum weld metal, Transactions of JWRI 2 (1973) 184-190.

[19] L. Beltran-Sanchez, D.M. Stefanescu. A quantitative dendrite growth model and analysis of stability concepts, Metall. Mater. Trans. A 35A (2004) 2471-2485. 
[20] T. Debroy, S.A. David. Physical processes in fusion welding, Rev. Mod. Phys. 67 (1995) 85-112.

[21] S.A. David, T. Debroy. Current issues and problems in welding science, Science 257 (1992) 497-502.

[22] H. Zhao, T. Debroy. Weld metal composition change during conduction mode laser welding of aluminum alloy 5182, Metall. Mater. Trans. B 32 (2001) 163-172.

[23] A. Arora, G.G. Roy, T. DebRoy. Unusual wavy weld pool boundary from dimensional analysis, Scripta Mater. 60 (2009) 68-71.

[24] K. Mundra, T. DebRoy, K.M. Kelkar. Numerical prediction of fluid flow and heat transfer in welding with a moving heat source, Numer. Heat Tr. A-appl 29 (1996) 115-129.

[25] W. Zhang, G.G. Roy, J.W. Elmer, T. DebRoy. Modeling of heat transfer and fluid flow during gas tungsten arc spot welding of low carbon steel, J. Appl. Phys. 93 (2003) 3022-3033.

[26] S. Mishra, T. DebRoy. A heat-transfer and fluid-flow-based model to obtain a specific weld geometry using various combinations of welding variables, J. Appl. Phys. 98 (2005) article number 044902 .

[27] H.L. Wei, J.J. Blecher, T.A. Palmer, T. Debroy. Fusion Zone Microstructure and Geometry in Complete-Joint-Penetration Laser-Arc Hybrid Welding of Low-Alloy Steel, Weld. J. 94 (2015) 135S-144S.

[28] A. De, T. DebRoy. Probing unknown welding parameters from convective heat transfer calculation and multivariable optimization, J. Phys. D - Appl. Phys. 37(1) (2004) article number PII S0022-3727(04)68775-4. 
[29] Y.C. Lim, X. Yu, J.H. Cho, J. Sosa, D.F. Farson, S.S. Babu, S. McCracken, B. Flesner. Effect of magnetic stirring on grain structure refinement Part 1-Autogenous nickel alloy welds, Sci. Technol. Weld. Joi. 15 (2010) 583-589.

[30] J.J. Blecher, T.A. Palmer, T. DebRoy. Solidification Map of a Nickel-Base Alloy, Metall. Mater. Trans. A 45A (2014) 2142-2151. 
Table 1 Chemical compositions of aluminum alloy 6082 (wt. \%) [13]

\begin{tabular}{ccccccccccccc}
\hline $\mathrm{Mg}$ & $\mathrm{Si}$ & $\mathrm{Fe}$ & $\mathrm{Mn}$ & $\mathrm{Cr}$ & $\mathrm{Ti}$ & $\mathrm{Ni}$ & $\mathrm{Cu}$ & $\mathrm{Zn}$ & $\mathrm{B}$ & $\mathrm{V}$ & $\mathrm{Zr}$ & $\mathrm{Al}$ \\
\hline 0.75 & 0.86 & 0.42 & 0.43 & 0.06 & 0.032 & 0.01 & 0.09 & 0.07 & 0.0001 & 0.01 & 0.003 & Bal. \\
\hline
\end{tabular}

Table 2 Data used for numerical calculations

\begin{tabular}{ll}
\hline Variables & Value \\
\hline Arc radius $(\mathrm{mm})$ & 1.8 \\
Arc energy efficiency & 0.80 \\
Solidus temperature $(\mathrm{K})$ & 855 \\
Liquidus temperature $(\mathrm{K})$ & 925 \\
Density of metal $\left(\mathrm{kg} \mathrm{m}^{-3}\right)$ & 2700 \\
Thermal conductivity of solid $\left(\mathrm{W} \mathrm{m}^{-1} \mathrm{~K}^{-1}\right)$ & 180 \\
Effective thermal conductivity of liquid $\left(\mathrm{W} \mathrm{m}^{-1} \mathrm{~K}^{-1}\right)$ & 376 \\
Effective viscosity of liquid $\left(\mathrm{kg} \mathrm{m}^{-1} \mathrm{~s}^{-1}\right)$ & 0.009 \\
Temperature coefficient of surface tension $\left(\mathrm{N} \mathrm{m}^{-1} \mathrm{~K}^{-1}\right)$ & -0.35 \\
Specific heat of solid $\left(\mathrm{J} \mathrm{kg}^{-1} \mathrm{~K}^{-1}\right)$ & 0.90 \\
Specific heat of liquid $\left(\mathrm{J} \mathrm{kg}^{-1} \mathrm{~K}^{-1}\right)$ & 1.18 \\
Coefficient of thermal expansion $\left(\mathrm{K}^{-1}\right)$ & $2.30 \times 10^{-5}$ \\
\hline
\end{tabular}

Table 3 GTA welding process parameters [13, 15]

\begin{tabular}{ccccc}
\hline Weld No. & Scanning speed $(\mathrm{mm} / \mathrm{s})$ & Current $(\mathrm{A})$ & Voltage $(\mathrm{V})$ & Average grain width $(\mu \mathrm{m})$ \\
\hline 1 & 2.0 & 170 & 10.7 & 80 \\
2 & 4.2 & 175 & 11.2 & 70 \\
3 & 8.0 & 184 & 11.2 & 50 \\
4 & 11.5 & 196 & 11.8 & 45 \\
\hline
\end{tabular}




\section{Figure Captions:}

Figure 1. The 3D orthogonal coordinates used in the calculations. $R_{\max }$ is the maximum solidification rate which equals the scanning speed, $R_{l o c}$ is the local solidification rate and $\alpha$ is the angle between the scanning direction and the maximum heat flow direction in the $x-y$ plane.

Figure 2. Computed temperature and velocity fields during GTA welding of aluminum alloy 6082, where the welds are moving in the $-\mathrm{x}$ direction. (a), (b) and (c) show the top horizontal $\mathrm{x}-\mathrm{y}$ plane $(\mathrm{z}=$ $3 \mathrm{~mm}$ ) and (d), (e) and (f) indicate the horizontal $x-y$ plane at the mid-depth of the weld $(\mathrm{z}=1.5 \mathrm{~mm})$ for $2.0 \mathrm{~mm} / \mathrm{s}, 8.0 \mathrm{~mm} / \mathrm{s}$ and $11.5 \mathrm{~mm} / \mathrm{s}$ scanning speeds, respectively.

Figure 3. A comparison of the experimentally determined FZ geometry with that computed using the heat transfer and fluid flow model for GTA welding of aluminum alloy 6082. Left part is experimentally observed cross section [15]. Right part is the calculated temperature and velocity fields. Welding current: $175 \mathrm{~A}$, voltage: $11.2 \mathrm{~V}$, scanning speed: $4.2 \mathrm{~mm} / \mathrm{s}$.

Figure 4. A schematic illustration of the growth of curved columnar grains in a horizontal $x-y$ plane of a weld. $\alpha_{1}, \alpha_{2}$, and $\alpha_{3}$ are angles between the scanning direction and the maximum heat flow directions.

Figure 5. Calculated solidification rate $\mathrm{R}$ at the $\mathrm{S} / \mathrm{L}$ interface across the $\mathrm{FZ}$ in the horizontal $\mathrm{x}$-y plane at the mid-depth $(\mathrm{z}=1.5 \mathrm{~mm})$ of GTA weld of aluminum alloy 6082 for different scanning speeds.

Figure 6. Calculated cooling rate GR at the S/L interface across the FZ in the horizontal $x-y$ plane at the mid-depth $(\mathrm{z}=1.5 \mathrm{~mm})$ of GTA weld of aluminum alloy 6082 for different scanning speeds.

Figure 7. Calculated $\mathrm{G} / \mathrm{R}$ at the $\mathrm{S} / \mathrm{L}$ interface across the $\mathrm{FZ}$ in the horizontal $x-y$ plane at the mid-depth $(\mathrm{z}=1.5 \mathrm{~mm})$ of GTA weld of aluminum alloy 6082 for different scanning speeds. 
Figure 8. Computed growth of curved columnar grains in a horizontal $x-y$ plane at mid-depth $(z=1.5$ $\mathrm{mm}$ ) of GTA weld metal of 6082 Aluminum alloy. The contours and vectors show the temperature and velocity fields in the liquid pool, respectively. Welding current: $170 \mathrm{~A}$, voltage: $10.7 \mathrm{~V}$, scanning speed: $2.0 \mathrm{~mm} / \mathrm{s}$, solidification time: $8.0 \mathrm{~s}$.

Figure 9. Curved columnar grains in a horizontal $x-y$ plane at the mid-depth $(z=1.5 \mathrm{~mm})$ of GTA weld of 6082 aluminum alloy. (a) Calculated results, (b) Experimentally observed results [13]. Welding current: $170 \mathrm{~A}$, voltage: $10.7 \mathrm{~V}$, scanning speed: $2.0 \mathrm{~mm} / \mathrm{s}$.

Figure 10. Curved columnar and equiaxed grains in a horizontal $x-y$ plane at mid-depth $(z=1.5 \mathrm{~mm})$ of GTA weld of 6082 aluminum alloy. (a) Calculated results, (b) Experimentally observed results [13]. Welding current: $184 \mathrm{~A}$, voltage: $11.2 \mathrm{~V}$, scanning speed: $8.0 \mathrm{~mm} / \mathrm{s}$.

Figure 11. Curved columnar and equiaxed grains in a horizontal $x$-y plane at mid-depth $(z=1.5 \mathrm{~mm})$ of GTA weld of 6082 aluminum alloy. (a) Calculated results, (b) Experimentally observed results [13]. Welding current: 196 A, voltage: $11.8 \mathrm{~V}$, scanning speed: $11.5 \mathrm{~mm} / \mathrm{s}$. 


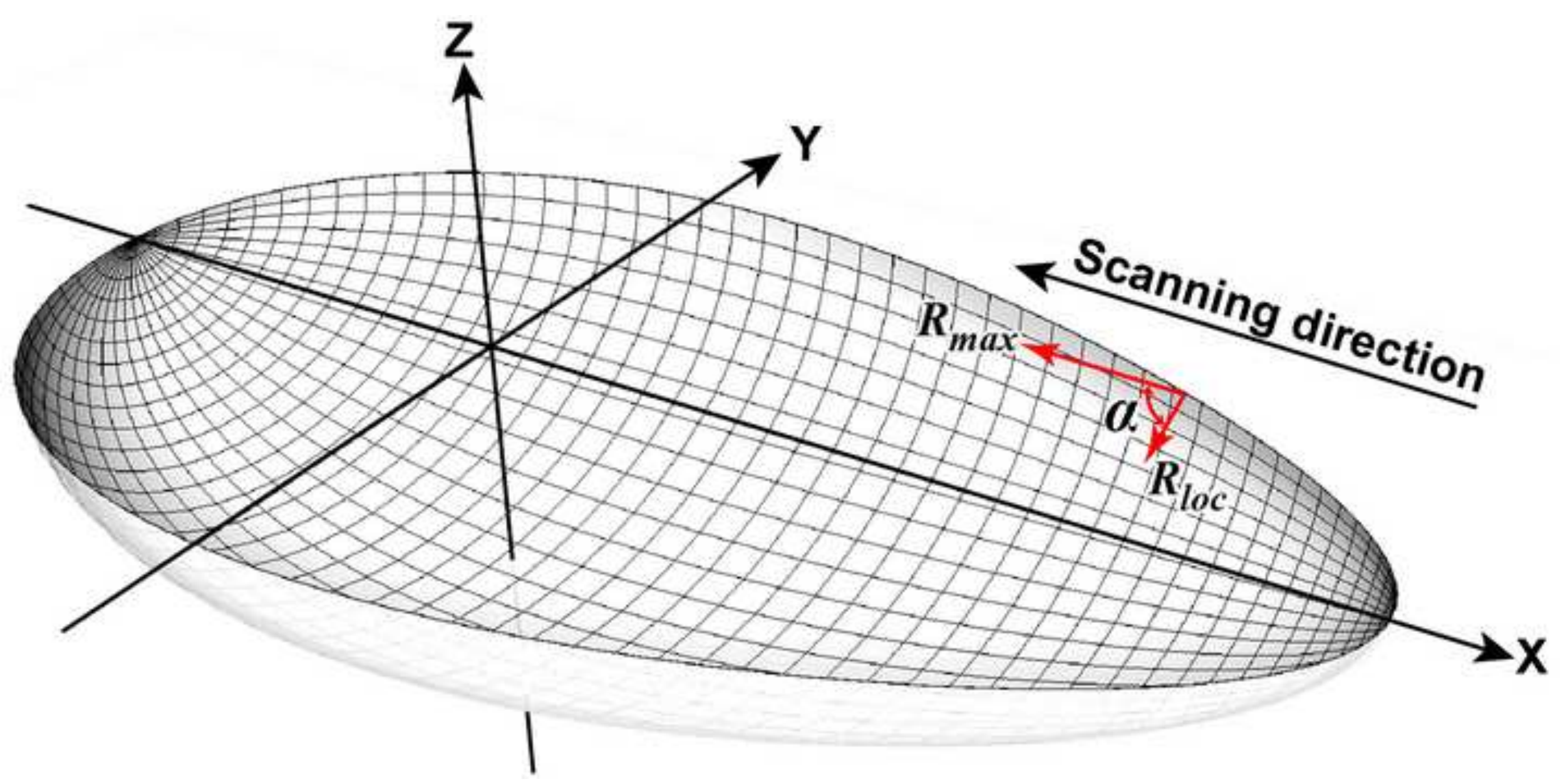



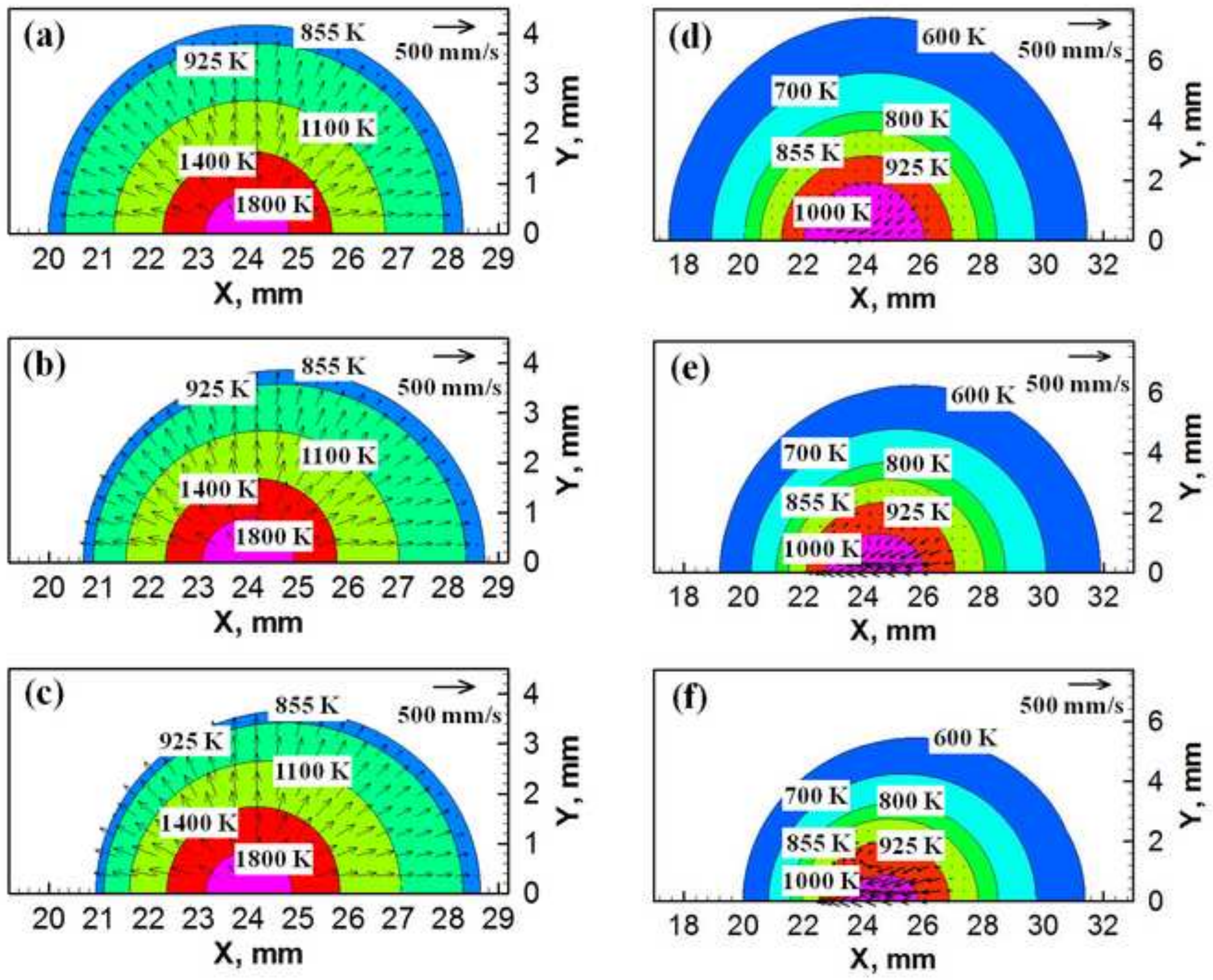


$$
4
$$

Scanning direction

\section{Curved}

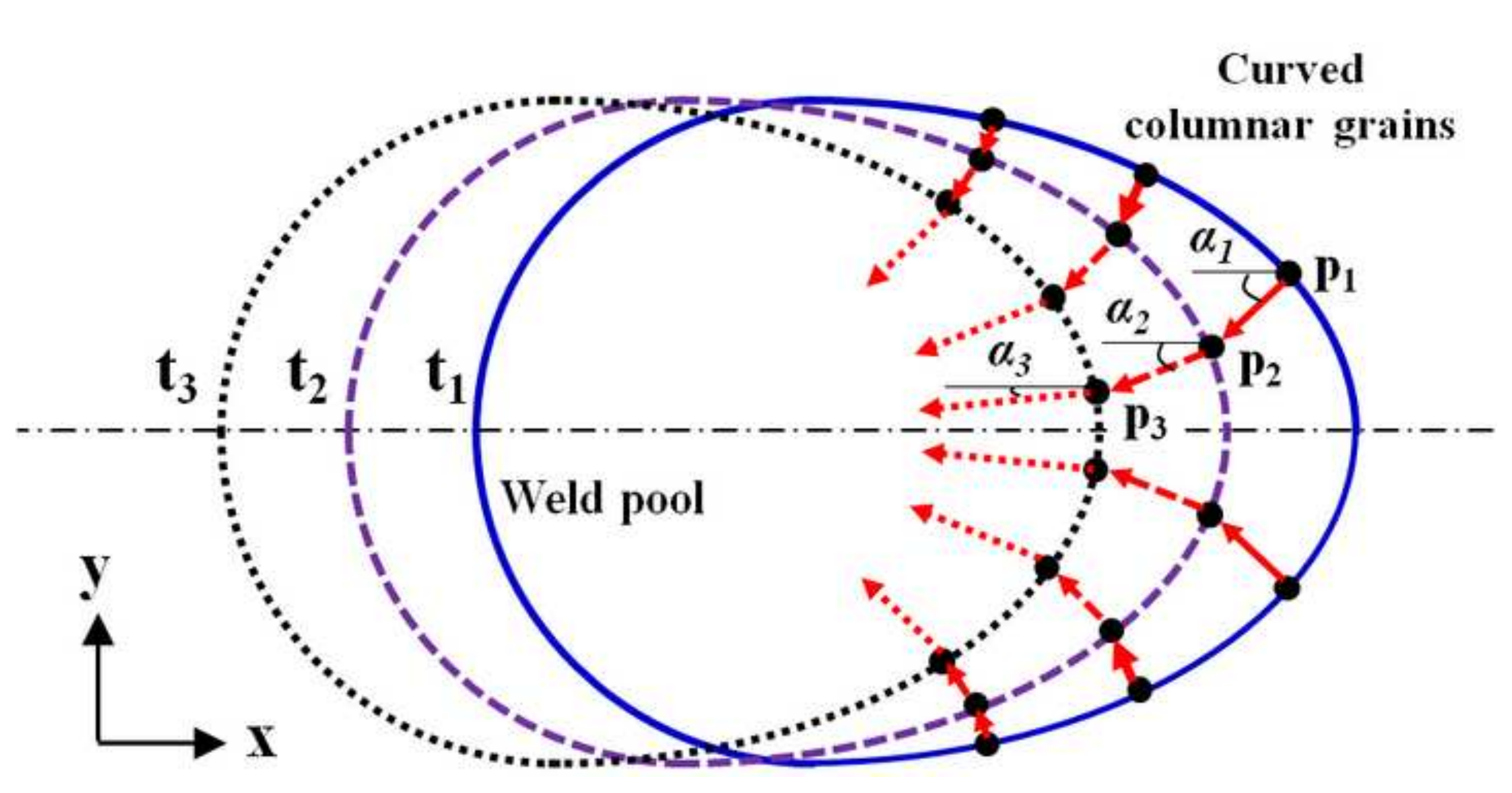




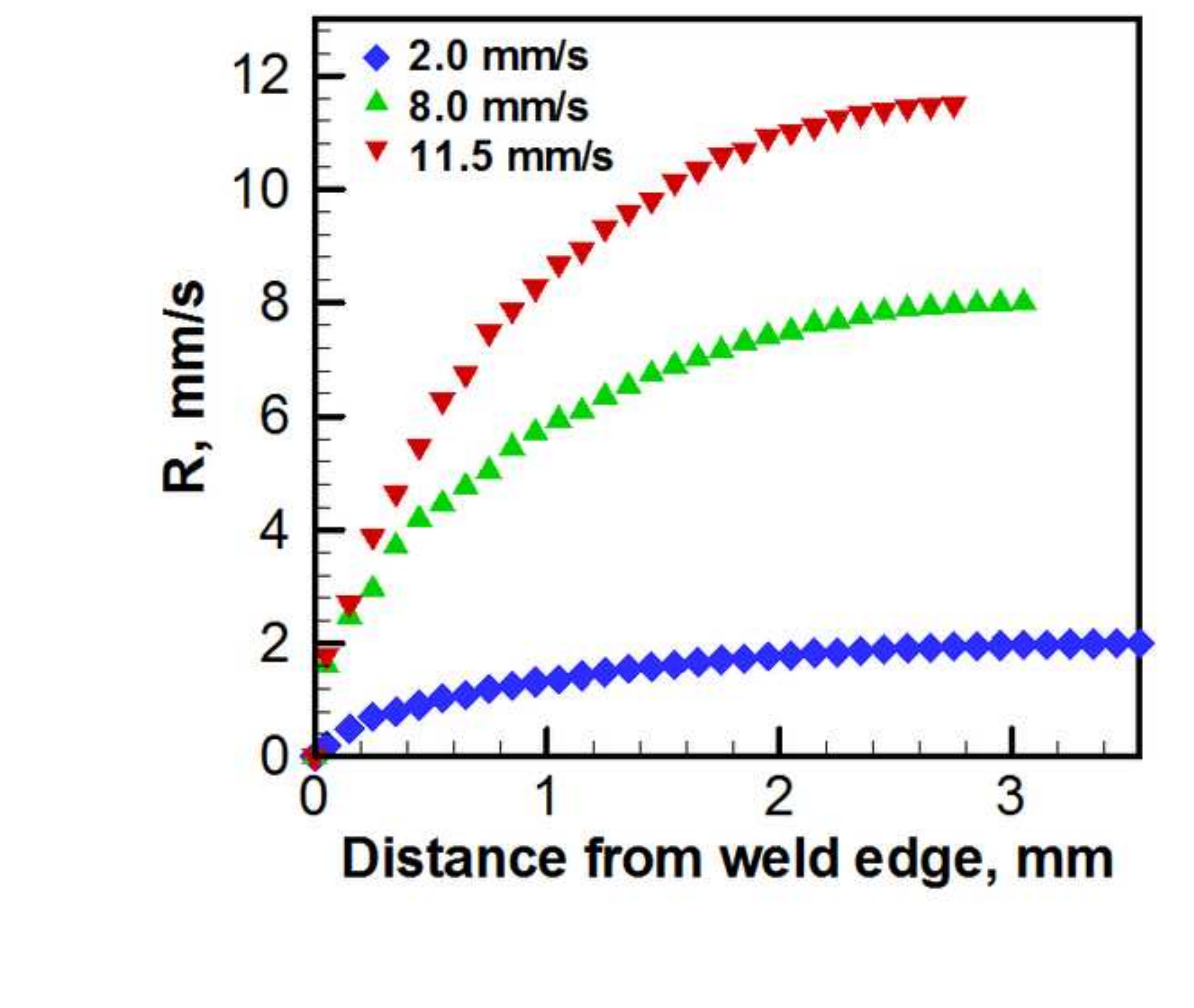

.

(
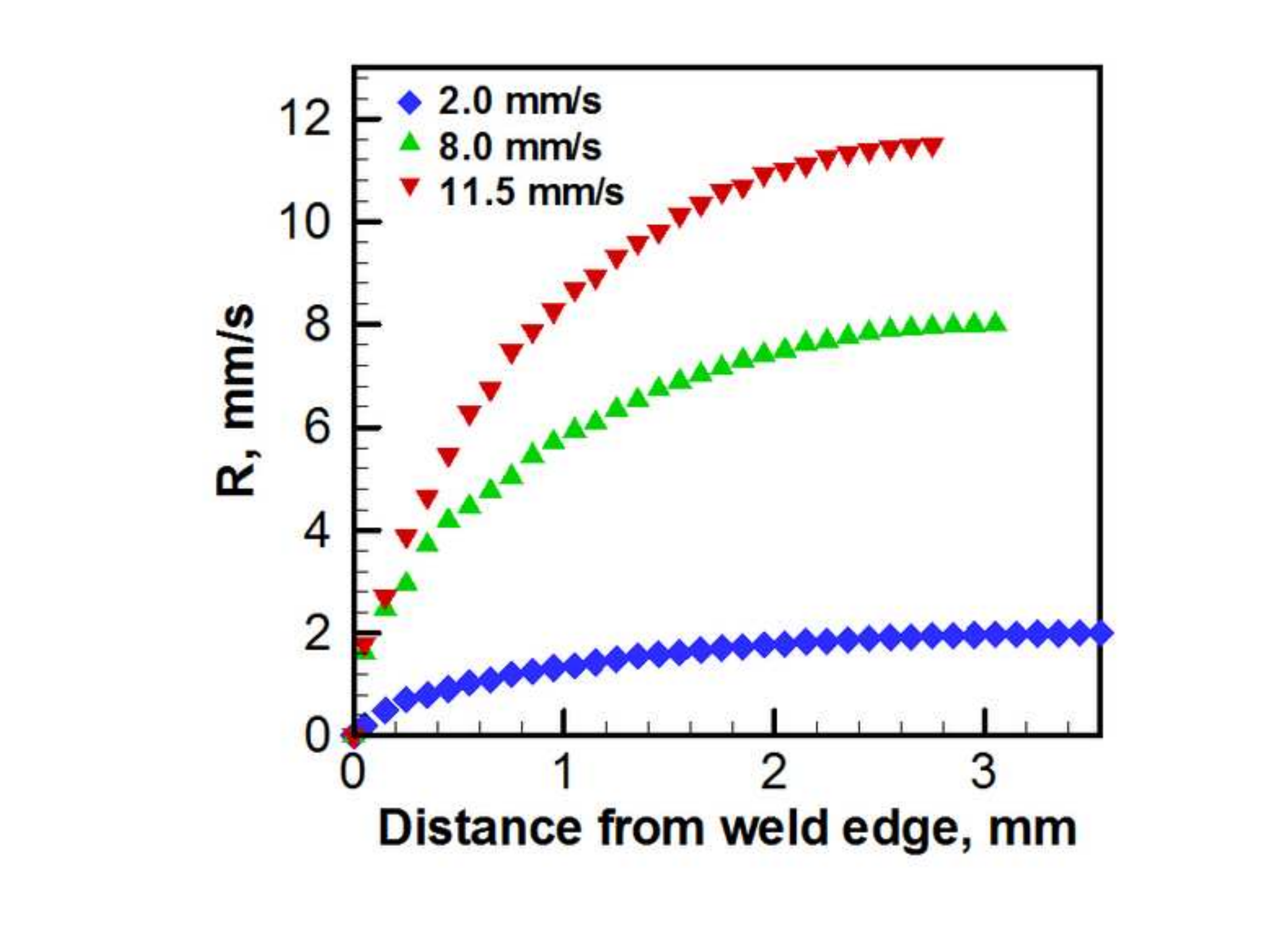

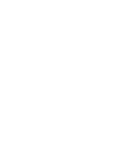




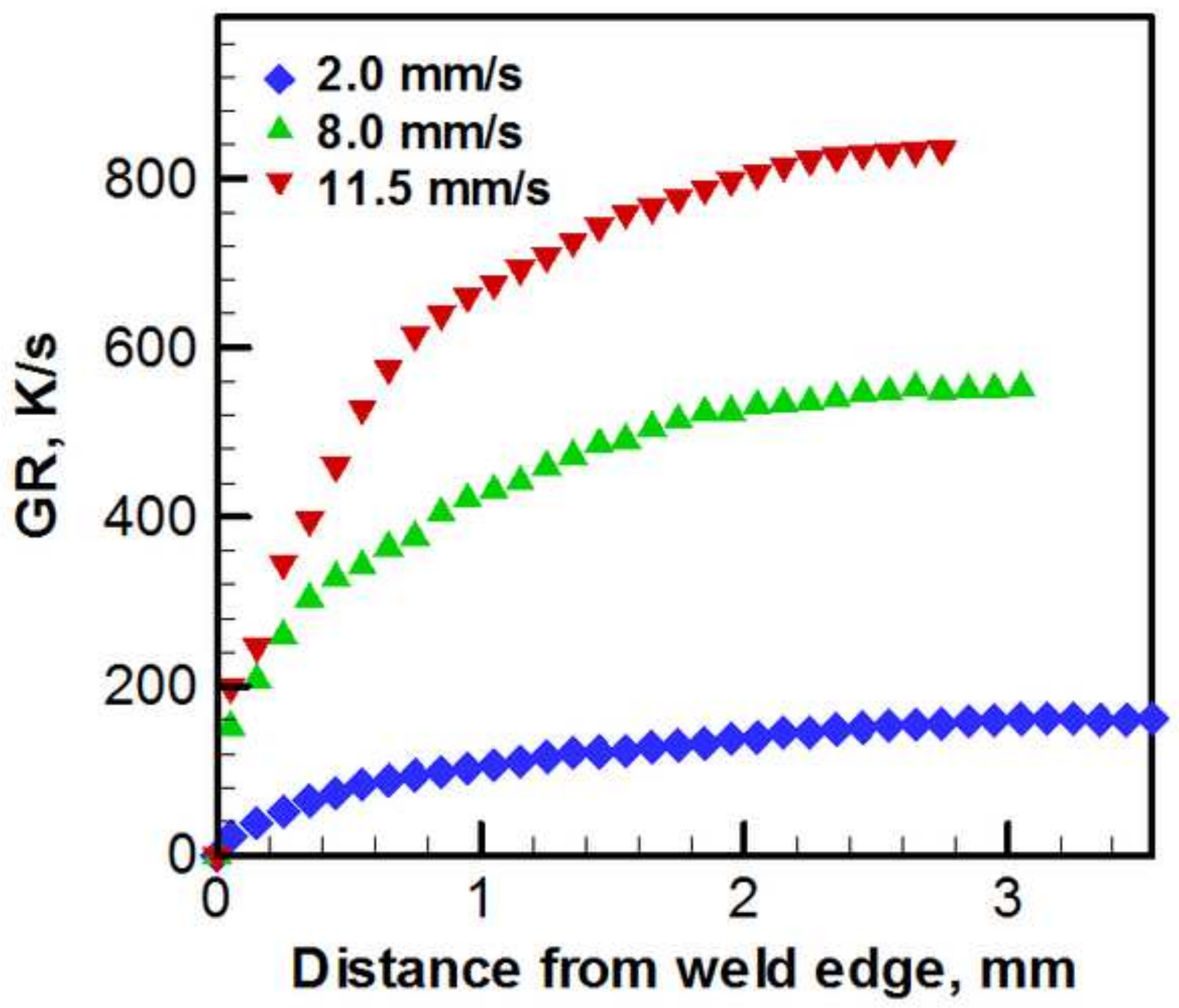



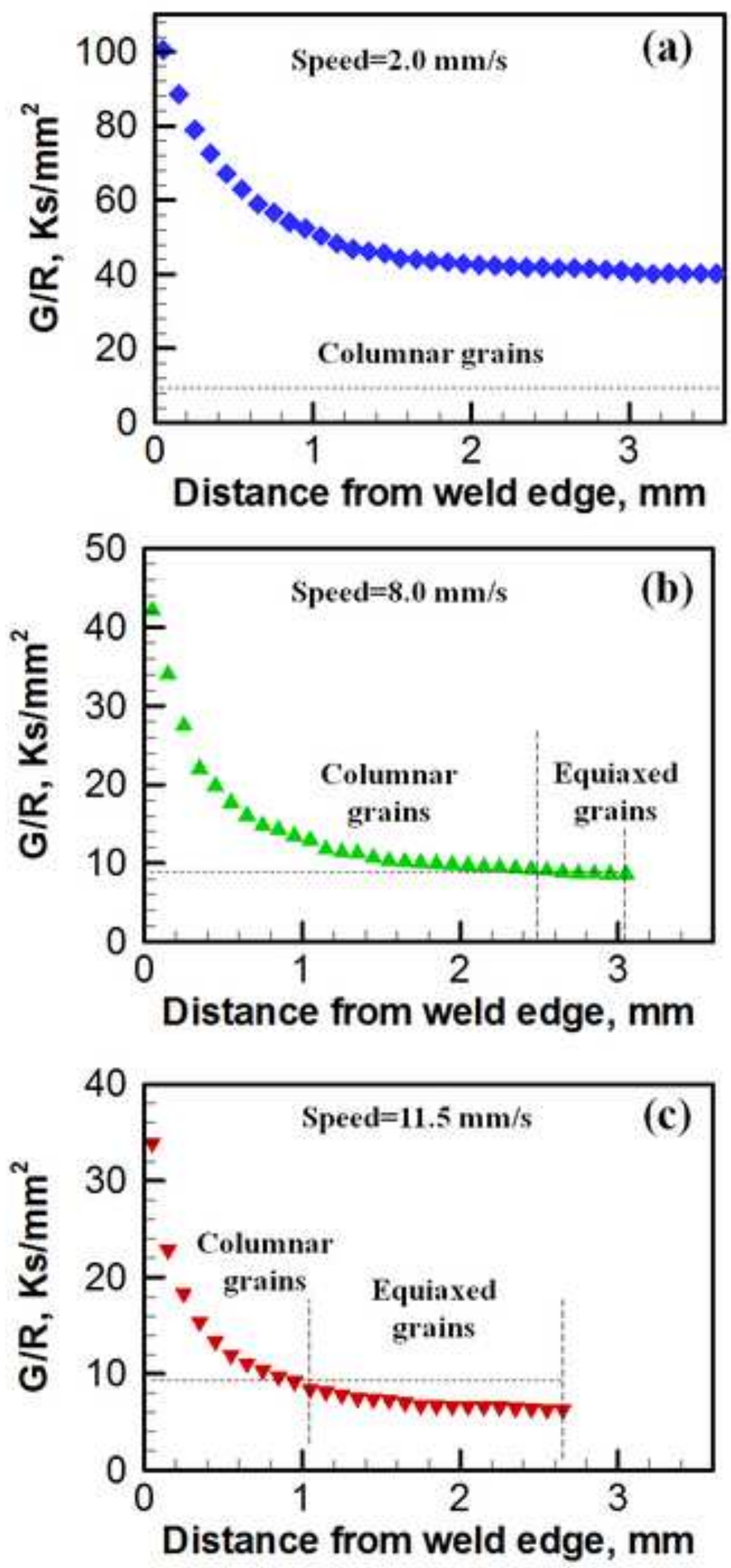

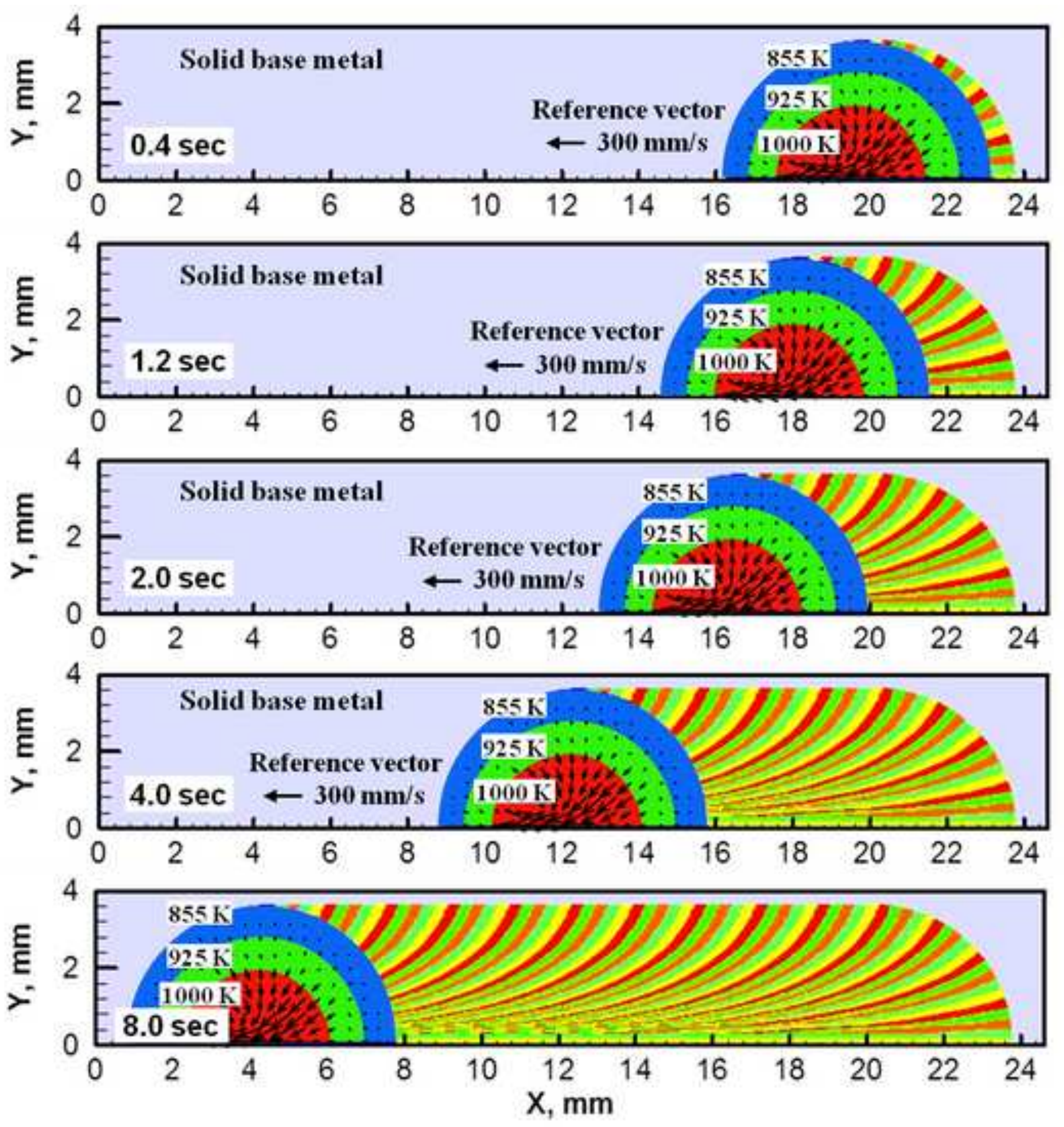

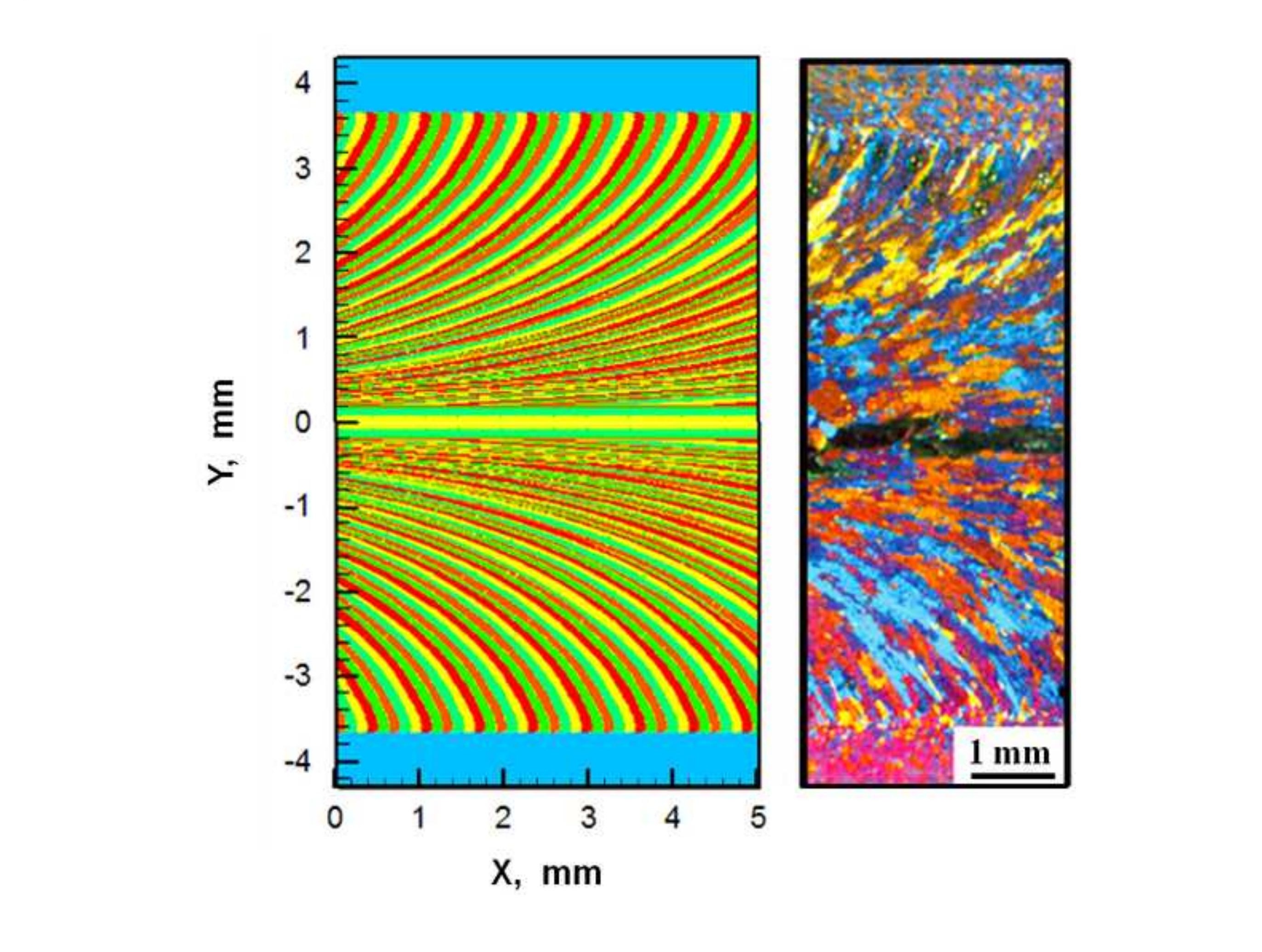

5

$$
\text { . }
$$
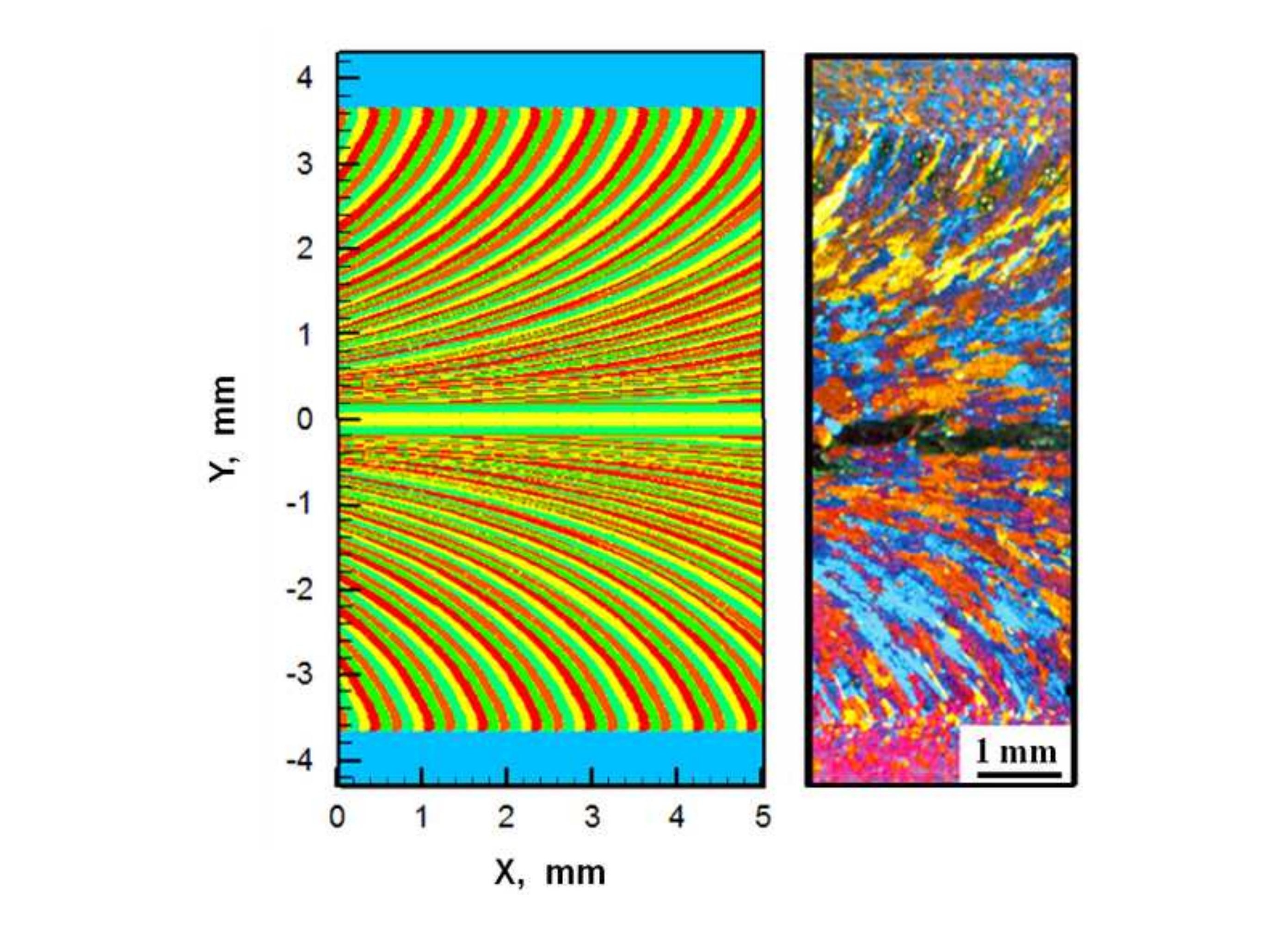

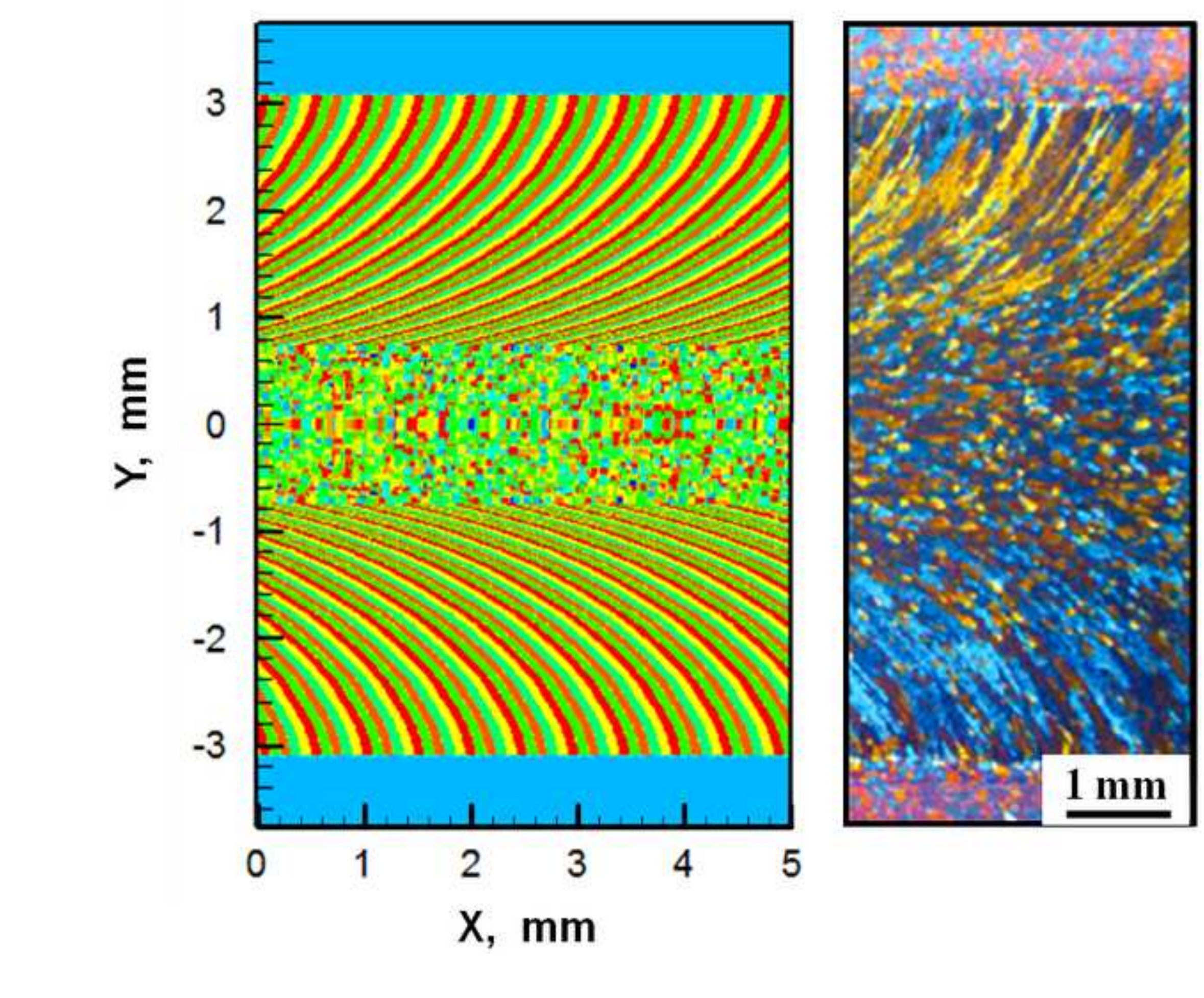

5
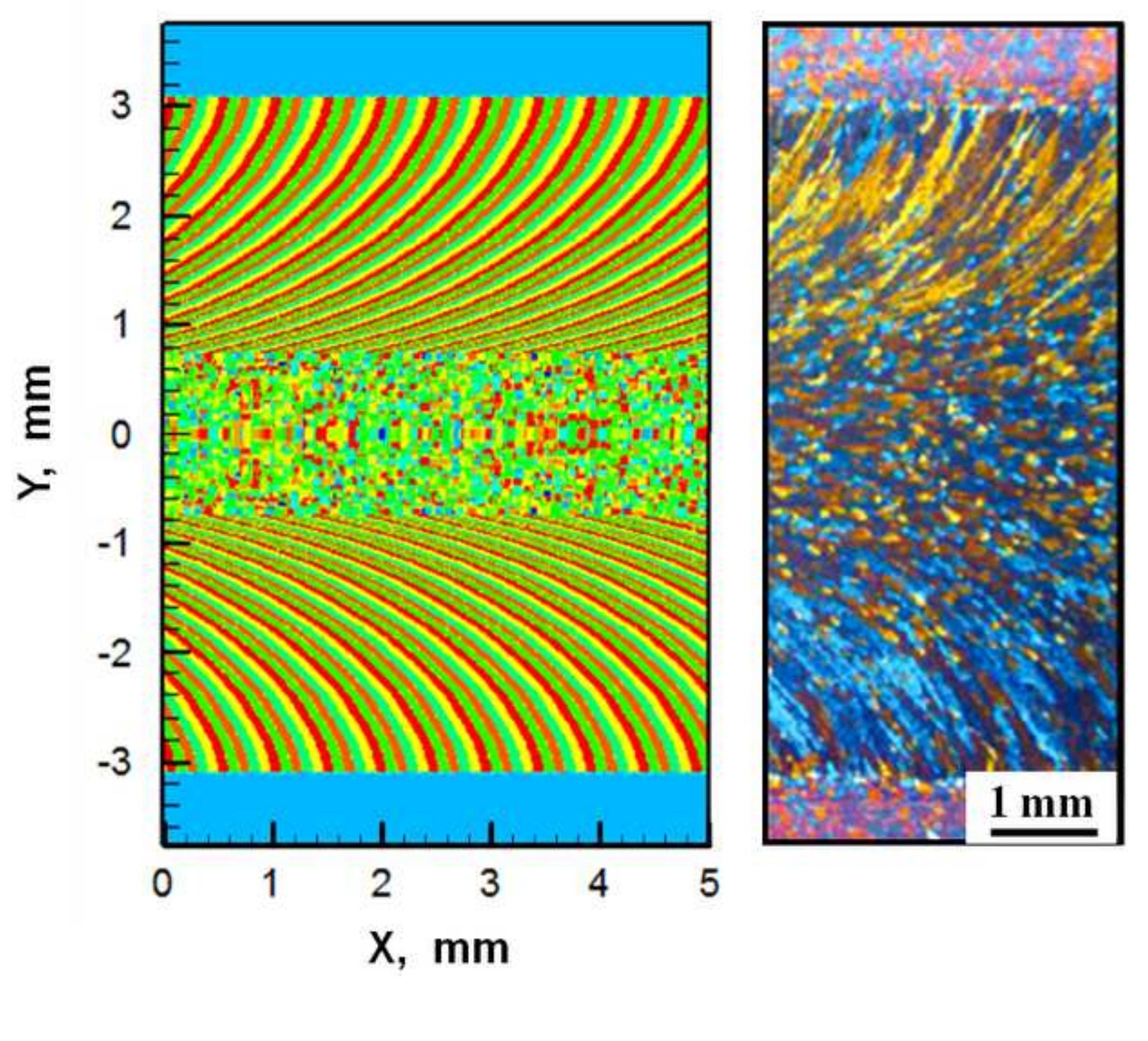

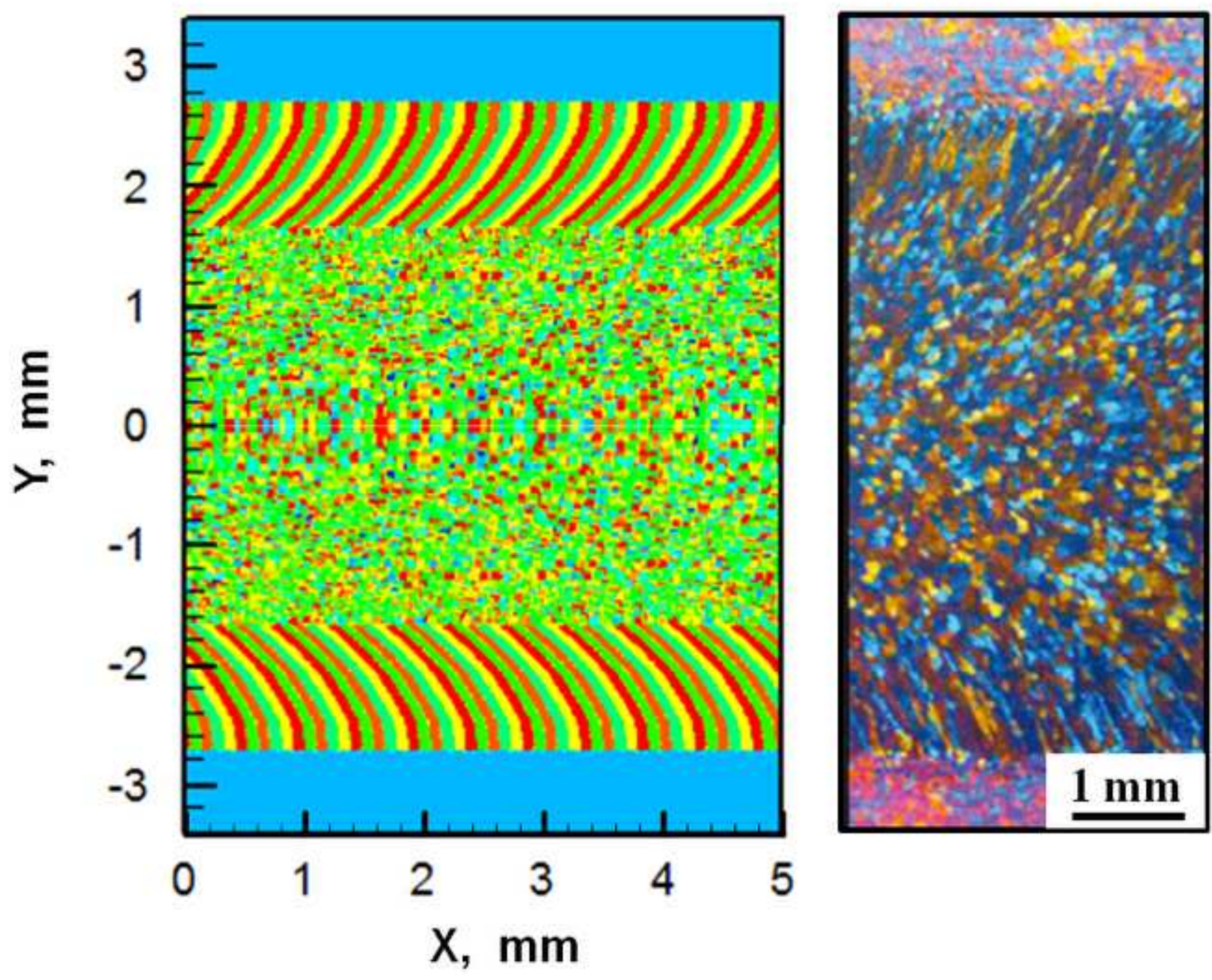

5

$1 \mathrm{~mm}$

$$
\text { . }
$$

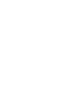

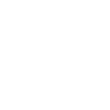



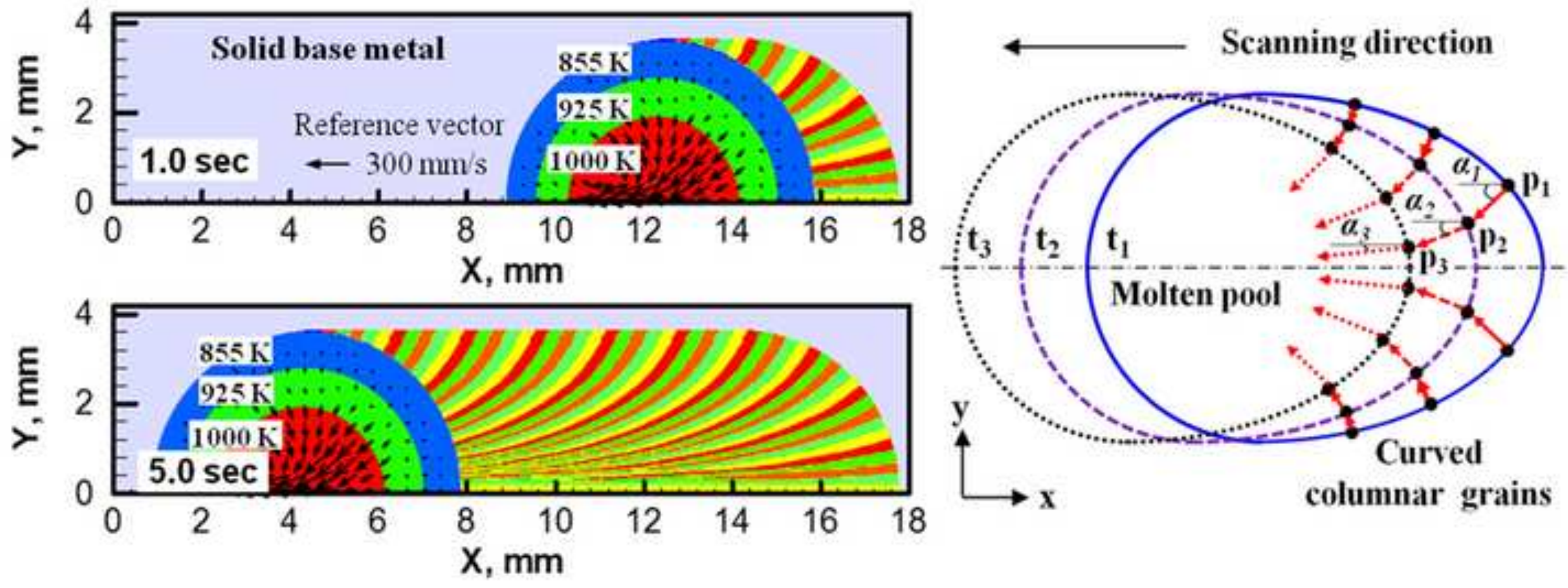